DOI: $10.4274 / \mathrm{tpa} .478$

\title{
Kikuchi-Fujimoto disease associated with hemophagocytic syndrome
}

\author{
Pamir Gülez1, Murat Hızarcıŏlu1', Ragıp Ortaç2 \\ 1Dr. Behçet Uz Cildren's Diseases and Surgery Education and Research Hospital, Department of Pediatrics, Izmir, Turkey \\ 2Dr. Behçet Uz Cildren's Diseases and Surgery Education and Research Hospital, Department of Pathology, Izmir, Turkey
}

\section{Summary}

Kikuchi-Fujimoto disease is a rare condition during childhood characterized with fever and cervical lymphadenopathy. Definitive diagnosis of the disease can only be made histologically on lymph node biopsy. Hemophagocytic syndrome associated with Kikuchi-Fujimoto disease is especially rare. In this article, we present a case of an eight years old girl diagnosed as hemophagocytic syndrome associated with KikuchiFujimoto disease. (Turk Arch Ped 2013; 48: 71-73)

Key words: Hemophagocytic syndrome, Kikuchi-Fujimoto disease, lymphadenopathy

\section{Introduction}

Kikuchi-Fujimoto disease (KFD) is an uncommon, idiopathic and generally self-limiting disease. Its etiology has not been elucidated fully. It occurs very rarely in children. The disease is characterized by fever and cervical lymphadenopathy. The definite diagnosis is made by examination of lymph node biopsy sample $(1,2)$. The disease is very rarely associated with hemophagocytic syndrome (HPS) $(3,4)$. In this article, an 8-yearold girl who was diagnosed as Kikuchi-Fujimoto disease associated with hemophagocytic syndrome was presented because this association is observed very rarely.

\section{Case}

An eight-year-old female patient presented with a complaint of lumps in the neck. Her medical history revealed no serious disease before. It was learned that the lump in the left side of her neck started one month ago, increased in size gradually and other lumps appeared in the other regions of her neck and above the clavicle. It was stated that she had fever during this period, fever could be decreased with antipyretics easly, but increased again and there was no loss of weight.

On physical examination, the body temperature was found to be $38.8^{\circ} \mathrm{C}$ (axillary). The body weight was found to be $21 \mathrm{~kg}$
(10-25 p), the height was found to be $1.20 \mathrm{~cm}(25-50 \mathrm{p})$, the cardiac apical pulse was found to be $92 / \mathrm{min}$ and the blood pressure was found to be $100 / 65 \mathrm{mmHg}$. The respiratory rate was found to be $28 / \mathrm{min}$ and the lung sounds were normal. Painful, mobile and soft lymph nodes were palpable in the left posterior region and right side of the neck (5-7 lymph nodes smaller than $1 \mathrm{~cm})$, in the left supraclavicular region $(4 \times 2 \mathrm{~cm})$ and in the left side of the neck $(2 \times 2 \mathrm{~cm})$. Other systemic findings were normal.

Laboratory findings were as follows: hemoglobin $9.5 \mathrm{~g} / \mathrm{dL}$, leukocytes $4920 / \mathrm{mm}^{3}$, platelets $285000 / \mathrm{mm}^{3}$, peripheal blood smear: PNL 25\%, lymphocytes \%65, monocytes \%10, atypical cells were not observed. Erythrocyte sedimentation rate (ESR) $101 \mathrm{~mm} / \mathrm{h}$, CRP 0,55 mg/dL, LDH 392 IU/L, ferritin $152 \mathrm{ng} / \mathrm{mL}$. Hepatic and renal function tests were found to be normal. Abdominal ultrasonography (USG) was found to be normal. On cervical USG; a lymph node with dimensions of 37x23×20 mm was found in the left supraclavicular region and three lymph nodes with the largest diameters being 23, 13 and $11 \mathrm{~mm}$ were found in the left side of the neck. No pathology was found on postero-anterior lung graphy and thoracic tomography. Bone marrow biopsy performed on the second day of her hospitalization was found to be normal. Serologic tests for Epstein-Barr virus, parvovirus B19, Mycoplasma pneumonia, cytomegalovirus, toxoplasma and rubella and group agglutinations were found to be negative. 
Fine needle biopsy was performed from the left supraclavicular lymp node. However, it was evaluated as undiagnostic fine needle aspiration biopsy cytology. Thereupon, excisional biopsy was performed from the left cervical lymph node. On examination of the lymph node by light microscope, the normal structure was found to be partially maintained and patch-like large necrosis areas containing nucleus particles and cellular debris were noted in areas where the normal structure was disappeared (Picture 1). On immunohistochemical examination, CD3+ T and CD20+B lymphocytes showed normal distribution in the partially maintained lymphoid tissue areas, while histiocyte clusters and CD68+ macrophages were observed around the necrosis foci (Picture 2). With these histopathological findings a diagnosis of KFD was made. The histopathological findings obtained were compatible with the literature $(5,6)$.

Ibuprofen was given to the patient who continued to have intermittent fever. On the 19th day of hospitalization hepatosplenomegaly was found in the patient who had no additional complaint and the laboratory findings were as follows: leucocyte number $2070 / \mathrm{mm}^{3}$, platelet number $82000 / \mathrm{mm}^{3}$, serum ferritin $22211 \mathrm{ng} / \mathrm{mL}$, triglyceride $285 \mathrm{mg} / \mathrm{dL}$, fibrinogen $262 \mathrm{mg} / \mathrm{dL}$, LDH $285 \mathrm{IU} / \mathrm{L}$, ESR $51 \mathrm{~mm} / \mathrm{h}$. Hepatic and renal function tests were found to be normal. HPS was considered with these findings. Hemophagocytosis was observed on examination of the bone marrow aspiration biopsy sample (Picture 3). Intravenous immunoglubulin was given for two days at a dose of $1 \mathrm{~g} / \mathrm{kg} /$ day. On the third day high dose methylprednisolone (30 mg/kg/day) was started. On the second day of high dose methylprednisolone treatment, the platelet count was measured to be $8000 / \mathrm{mm}^{3}$. Platelet suspension was given by apheresis. However, the patient was taken to the intensive care unit because of acutely developing seizures (involving the right side), anisocoria, superficial respiration and development of bradicardia. At this time, the blood pressure was measured to be $105 / 70 \mathrm{mmHg}$. Mechanical ventilation was

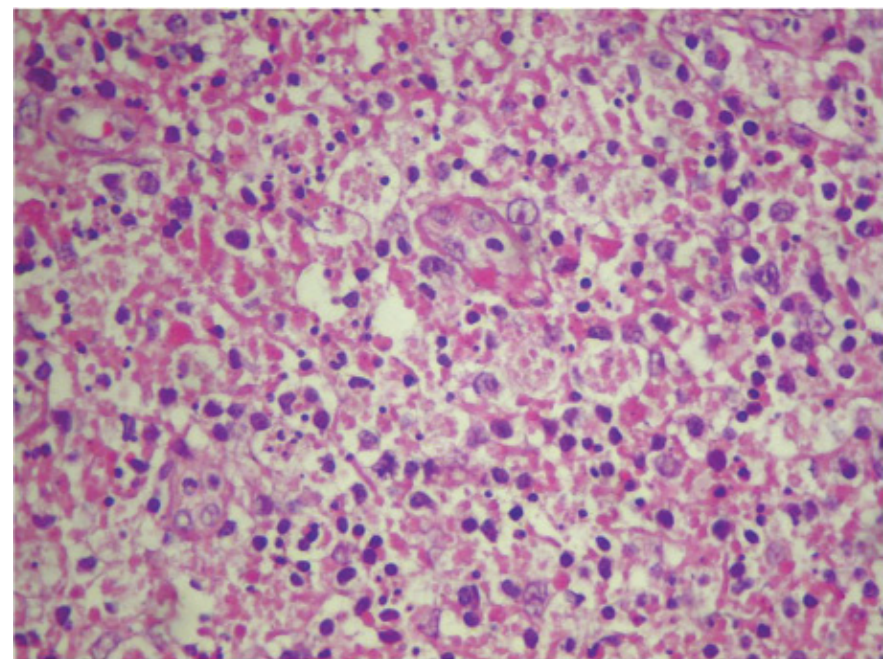

Picture 1. Lymph node showing diffuse necrosis and segmentation $(x 400, \mathrm{HE})$ started, but the patient was lost after a short while. PT anda PTT values measured at that time were found to be normal. Considering the physical examination and laboratory findings and the fact that she was lost in a very short time it was thought that she died because of intracranial bleeding due to thrombocytopenia. The definite cause of death could not be determined, since the family did not give consent for autopsy.

\section{Discussion}

Kikuchi-Fujimoto disease occurs more commonly in Easth Aisa and in women below the age of 30 . It occurs rarely in children. Autoimmune and viral causes are considered in the etiology of Kikuchi-Fujimoto disease. The disease is characterized by fever and cervical lympadenopahty. The definite diagnosis is made by examination of the lymph node biopsy sample. There is no specific treatment for the disease. Non-steroid anti-inflammatory drugs are given in presence of

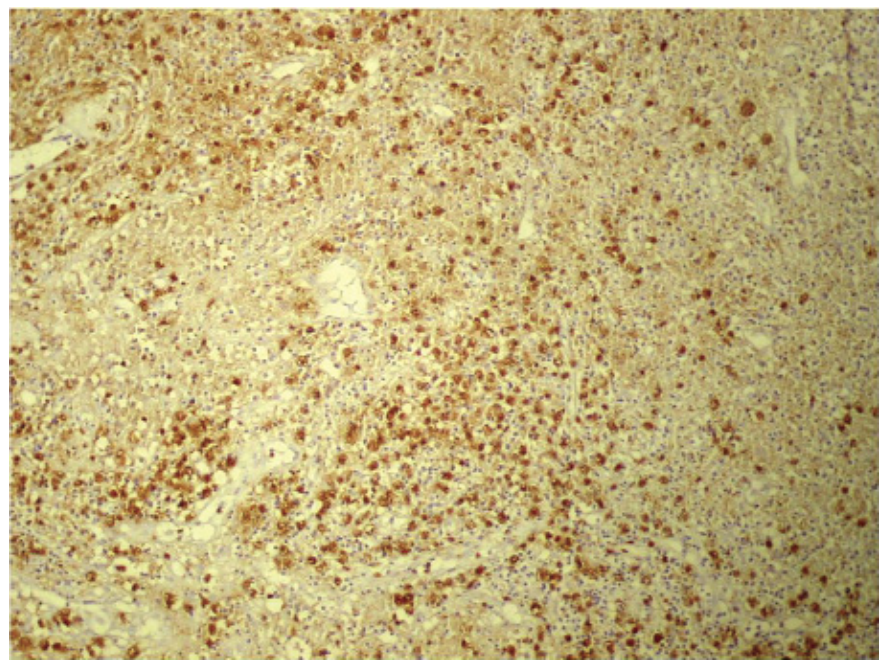

Picture 2. Dense histiocyte groups stained with CD68 ( $x 100$, DAB)

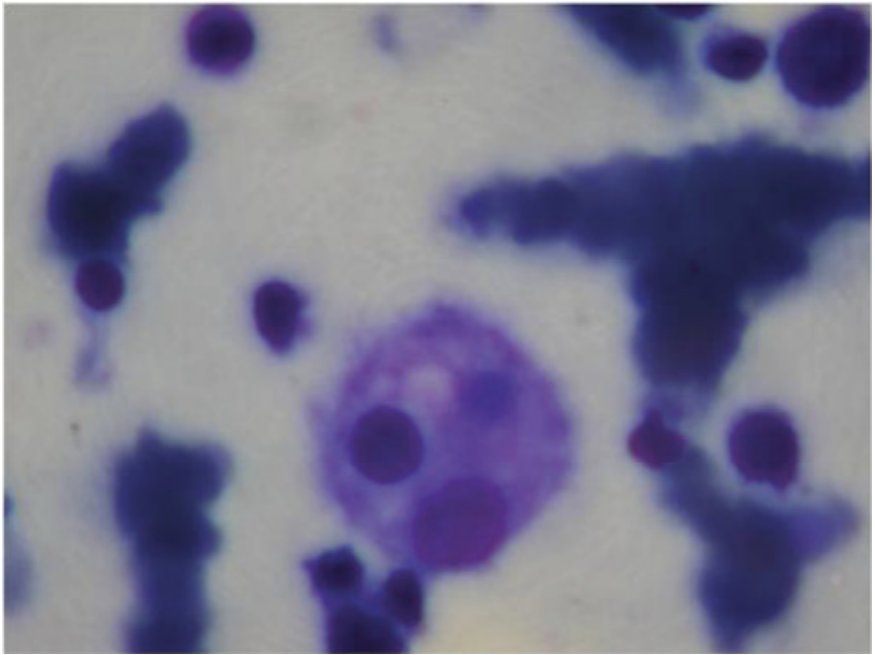

Picture 3. Hemaphagocytosis in the bone marrow (x100,Giemza) 
fever and pain related to tension in the lymph nodes. In presence of severe extralymphatic or invasive disease, recurrent disease or in milder cases where fever lasts more than 2 weeks, oral steroid treatment is used $(1,2,6,7)$. In a study, it was reported that high dose methylprednisolone treatment treated the disease in all subjects (8). The differential diagnosis includes especially lymphoma, tuberculosis and systemic lupus erythematosus. The disease is usually benign and is over in 1-4 months $(1,2,7)$. Very few number of pediatric patients has been reported to be lost in the literature (1). The patients are lost because of cardiac failure due to cytokine-mediated myocardial damage, hepatic failure due to hepatic involvement and HPS (9). A patient with recurrent KFD was lost because of intracranial bleeding related to thrombocytopenia (10).

The first pediatric case diagnosed as Kikuchi-Fujimoto disease was published in 1990 (11). According to our research, one pediatric case from our country was published in the literature in the English language and one pediatric case was published in journals included in ULAKBIM Turkish database $(12,13)$. Accordingly, our patient is the third pediatric KFH patient published from our country and is the first pediatric patient with KFD associated with HPS.

Some cytokines have been found with very high rates in the acute phase of the disease in Kikuchi-Fujimoto disease. These high levels of cytokines induce excessive histiocyte activation as in HPS and this may explain the development of HPS in some patients with KFD (8). There are few number of pediatric cases with KFD associated with HPS in the literature $(3,4)$. Only one of these six patients mentioned in the literature was lost because of severe infection related to severe neutropenia $(3,4)$. The diagnosis of HPS is made according to the diagnositc criteria determined by hemophagocytic lymphohistiocytosis (HLH) study group in 2004. In the classification made by this group, KFD is among the secondary HPS causes (14). According to this, in patients excluding the ones with familial hemophagocytic lymphohistiocytosis (FHL), presence of five of the following eight criteria is enough for the diagnosis of HPS: fever above $38,5^{\circ} \mathrm{C}$ for 7 days or longer, splenomegaly, cytopenia found in 2-3 series in the peripheral blood $\left(\mathrm{Hb}<9.0 \mathrm{~g} / \mathrm{dL}\right.$, platelets $<100000 / \mathrm{mm}^{3}$, absolute neutrophil count $<1000 / \mathrm{mm}^{3}$ ), hypertriglyceridemia and/or hypofibrinogenemia, hemophagocytosis in the bone marrow, spleen or lymph node, decreased activity of natural killer (NK) cells or absence of activity of NK cells, hyperferritinemia (>500 ng/mL), increased sCD25 (slL2 r) (>2400 U/mL) (14). In our patient, the presence of five diagnostic criteria including fever, splenomegaly, cytopenia, hypertriglyceridemia, hyperferritinemia and hemophagosytosis was shown. There is no consensus on the treatment of HPS associated with KFD yet. Some authors recommend to start with oral prednisolone and intravenous immunoglobulin because the disease has a more benign course in children compared to adults and to use $\mathrm{HLH}$ 2004 treatment methods in nonresponsive patients $(3,4)$. In some studies, it is stated that HPS is a serious condition and therefore high dose methylprednisolone (8), intravenous immunoglobulin (15) or HLH 2004 (14) method should be used in treatment. Although we administered a more intensive treatment in our patient, we could not stop the process and lost our patient.

This article was presented because both this disease and its association with HPS occur very rarely in the childhood and we wanted to emphasize that this disease should be considered in patients who present with fever and cervical lymphadenomegaly and in whom the initial tests do not indicate any clues related to another disease

\section{References}

1. Küçükardalı Y, Solmazgül E, Kunter E, Öncül O, Yıldııım Ş, Kaplan M. Kikuchi-Fujimoto Disease: analysis of 244 cases. Clin Rheumatol 2007; 26(1): 50-54.

2. Zou CC, Zhao ZY, Liang L. Childhood Kikuchi-Fujimoto disease. Indian J Pediatr 2009; 76(9): 959-962.

3. Lim GY, Cho B, Chung NG. Hemophagocytic lymphohistiocytosis preceded by Kikuchi disease in children. Pediatr Radiol 2008; 38(7): 756-61.

4. Kim YM, Lee YJ, Nam SO, Park SE, Kim JY, Lee EY. Hemophagocytic syndrome associated with Kikuchi's disease. J Korean Med Sci 2003; 18(4): 592-4.

5. Kuo TT. Kikuchi's disease (histiocytic necrotizing lymphadenitis). A clinicopathologic study of 79 cases with an analysis of histologic subtypes, immunohistology, and DNA ploidy. Am J Surg Pathol 1995; 19(7): 798-809.

6. Hutchinson CB, Wang E. Kikuchi-Fujimoto disease. Arch Pathol Lab Med 2010; 134(2): 289-293.

7. Yalçın S, Toprak SK, Erişmiş B, Altundağ Ö, Özdemir H, Topçuoğlu N. Management of Kikuchi-Fujimoto disease using glucocorticoid: a case report. Case Report Med 2011; 2011: 230840.

8. Yoshioka K, Miyashita T, Nakamura T, Inoue T, Yamagami K. Treatment of histiocytic necrotizing lymphadenitis (Kikuchi's disease) with prolonged fever by a single course of methylprednisolone pulse therapy without maintenance therapy: experience with 13 cases. Inter Med 2010; 49(20): 2267-2270.

9. Chan JK, Wong KC, Ng CS. A fatal case of multicentric Kikuchi's histiocytic necrotizing lymphadenitis. Cancer 1989; 63(9): 1856-1862.

10. Cheng CY, Sheng WH, Lo YC, Chung CS, Chen YC, Chang SC. Clinical presentations, laboratory results and outcomes of patients with Kikuchi's disease: emphasis on the association between recurrent Kikuchi's disease and autoimmune diseases. J Microbiol Immunol Infect 2010; 43(5): 366-371.

11. Song SY, Kwon WH, Han CH, Chung HR, Kim SY, Kwon YD. A case of subacute necrotizing lymphadenitis. J Korean Pediatr Soc 1990; 33: 714-720.

12. Emir S, Gögüş S, Güler E, Büyükpamukçu M. Kikuchi-Fujimoto disease (histiocytic necrotizing lympadenitis) confused with lymphoma in a child. Med Pediatr Oncol 2001; 37: 546-548.

13. Kantar M, Kadıoğlu B, Hekimgil M, Soydan S, Aksoylar S, Çetingül N, Kansoy S. Çocuklarda lenfadenopati ayırıcı tanısında seyrek görülen bir durum: Kikuchi-Fujimoto hastalığı. Çocuk Sağlığı ve Hastalıkları Dergisi 2008; 51: 153-157.

14. Henter JI, Horne A, Aricó M, Egeler RM, Filipovich AH, Imashuku S, Ladisch S, McClain K, Webb D, Winiarski J, Janka G. HLH-2004: Diagnostic and therapeutic guidelines for hemophagocytic lymphohistiocytosis. Pediatr Blood Cancer 2007; 48(2): 124-131.

15. Noursadeghi M, Aqel N, Gibson P, Pasvol G. Successful treatment of severe Kikuchi's disease with intravenous immunoglobulin. Rheumatology (Oxford) 2006; 45(2): 235-237. 